\section{Accident Prevention}

\section{In Sanitation}

\author{
By Edgar F. Seagle, M.S.P.H.
}

I HE ESSENTIAL points of this paper have been used to introduce to local health department personnel in North Carolina the close relationship between good sanitation practice and accident prevention. This concept of sanitation, though obvious in principle, seems to be difficult for many health workers to visualize in specific terms. The following examples, presented at State and local health staff conferences, appear to have improved acceptance and understanding of this concept and to have advanced and encouraged its many applications, with good results for sanitation all around.

A change of concepts has been characteristic of the progress of sanitation services. For example, not too many years ago sanitarians dressed like policémen and worked principally on the basis of enforcing laws which neither they nor their clients thoroughly understood. Sanitarians today dress like teachers or salesmen, and they work primarily to promote sanitation on its own merits, with a foundation of public acceptance, understanding, and approval. The word sanitation itself illustrates how concepts have changed. For many years, it has been associated primarily with cleanliness. But its original meaning was the protection of health; and that original meaning is restored to the extent that sanitarians broaden their responsibility and understanding.

Accident prevention is one program for protecting health which forces sanitarians to look

Mr. Seagle is sanitation consultant with the accident prevention section of the division of epidemiology, North Carolina State Board of Health, Raleigh, N.C. This accident prevention project is sponsored by the W. K. Kellogg Foundation. beyond details of neatness and cleanliness toward the true objectives of their work. At the same time, accident prevention enjoys much broader public understanding and acceptance than the processes of preventing contamination of food by invisible microbes. It is not only within full ken of human experience, but it also appeals directly to self-interest. Everyone is certain to be more concerned with a possible accident to themselves than with the uncertain and indirect effects of his habits on others.

\section{Control of Hazards}

To illustrate how accident prevention can play an important role in the improvement of sanitation, consider first the food handler working in the kitchen of a restaurant. If this person has an open cut or wound on his hand while preparing certain foods, the potential for contaminating this food with infectious bacteria is certainly high. Of course, if this person has been well schooled in proper food handling, he would not work with an open cut, but how many are so trained? The safe approach is to prevent such an accidental cut if possible. In one instance, every time a food handler reached for a certain pan he either scratched or cut his hand on a sharp edge of metal on the side of the storage cabinet. If this environmental hazard had been corrected, the food handler would not have had so many cuts. At the same time, his potential of food contamination would have been less. The manager might be induced to correct such conditions more readily if the element of personal pain and suffering, as well as liability for workman's compensation, had been discussed along with the food infection hazard. This approach also gives a client the feeling that you are interested in him personally and helps to secure cooperation.

Sanitarians have long been concerned with the cleanliness of floor and wall surfaces. To maintain cleanliness they should be made of smooth, washable, nonabsorbent material, free from cracks, crevices, and open joints. Such a surface certainly is a poor place for germs to 
take a foothold. It also, however, contributes to safe walking and movement on the premises. The fact that floor surfaces, if properly constructed, contribute not only to cleanliness but to safety is another example of how accident prevention can strengthen a sanitation program. It also illustrates that sanitarians have been engaged in accident prevention often without directly realizing what they have achieved.

Restaurant and meat market regulations usually require adequate lighting and ventilation. Here again these regulations were primarily set up in the interest of cleanliness; that is, if you can see dirt, you can clean it up. Another important advantage in good lighting though is to reduce accidents. Poorly lit cellars or stairs need no comment: Their high potential as a source of falls resulting in disabilities and death is too well known. Good lighting is certainly needed to see that equipment is effectively washed and cleaned. However, good lighting at the cutting, mixing, or grinding table in the kitchen may prevent a slash to a finger or hand. Many a hand is caught in a piece of equipment because the moving parts are not clearly seen in a dim light. Here again, the accident prevention concept for the operator or foodhandler is a strong supplement to sanitation.

Garbage cans also may figure in preventing accidents. For example, many garbage cans of food-handling establishments sit on back platforms, to be emptied daily. When there are enough cans, there is less spilling refuse and other wastes and the walking area is more likely to be dry and clear. However, if garbage cans overflow, meat scraps, bones, rubbish, offal, filth and other wastes are strewn over the back platforms and eventually are kicked or carried into the kitchen. Articles of this kind provide a slippery underfooting and may provoke a bad spill or fall as much as a broom or other heavy litter in the walking area. Therefore, walkways clear of garbage discourage breeding of flies, rodents, and germs, but also discourage the chances of accidental falls.

It is recommended that merchandise in the storage room be stored on elevated platforms to facilitate cleaning. If this recommendation is carried out, things are certain to be more in order than if they are strewn on the floor at random. Here also, the possibility of tripping and falling is reduced. Again, neatness and accident prevention join in the common cause of sanitation.

\section{Farm Sanitation}

Examples of sanitation improvement by eliminating accident producing environmental conditions can be found also on farms and in dairies. Uncovered holes or slick surfaces on graded levels around the barn may result in cows slipping and injuring their udders. Such injuries in turn may produce mastitis. Mastitis means not only an economic loss to the farmer but may also mean a possible danger of infection in the milk. However, an employee or the farmer himself may fall and break a leg in these same danger spots. Therefore, if farm sanitation work is done with an eye towards protecting the farmer as well as the cow from accident, both may benefit. Such hazards are typified also by discarded pit privies. If these are effectively filled in, there is less possibility of spreading disease; however, the fill also reduces the chances for an accident. Discarded wells also should be filled in or securely covered, for similar reasons.

As to insect and rodent control, the North Carolina State Board of Health is pursuing a project which although designed primarily to prevent mosquito breeding also prevents many home accidents. This project is that of inspecting every home and farm pond and stressing that all tree stumps and other obstructions be completely cleared from the pond bed. The regulation calls only for these stumps to be a certain number of inches below the fluctuating water level. However, sanitarians strongly recommend complete clearing of the pond bed. They then accomplish both the primary purpose and also eliminate the chance that swimmers diving in the pond may hit their heads on these obstructions, as well as the threat to boats on the larger ponds. If a farmer is reluctant to believe that these stumps have any important relation to mosquito breeding, he may be more readily convinced that some member of his family can be seriously injured or killed if the stumps remain. 
There are many other examples of the close relationship between accident prevention and other phases of sanitation.

In North Carolina, studies have shown that there were 825 accidental deaths in 1954 on the farm and in the home. This is a rate of approximately 2 deaths per day. It has been estimated that for each of these fatal accidents, there are 150 accidental injuries resulting in disability for 24 hours or longer, and 4 of these are permanent disabilities. Any accident prevention activity should be preceded by an inservice training program for sanitarians and a check list of home hazards agreed upon and approved. Armed with this knowledge, the sanitarian could then discuss such situations on the spot and make recommendations for the most practical means of elimination or correction. Such a program may be used by all categories of public health personnel who visit the public in their daily duties. Accidents are unquestionably one of the major health problems. Sanitation personnel have a great opportunity to combine accident prevention activities with their existing programs. Such a forceful combination would add even greater satisfaction to their present valuable work.

\section{Galactosemia Cause Found}

The cause of galactosemia, also known as galactose diabetes, an often fatal metabolic disease of children, has been discovered by scientists of the National Institute of Arthritis and Metabolic Diseases, Public Health Service. It was reported in official announcements on March 12, 1956.

This disease ordinarily appears within a few days after birth. The infant suffering from galactosemia is unable to utilize or even tolerate milk in any form. Lactose, often called milk sugar, contains another sugar, galactose. This substance cannot be handled by the child's system if he has galactosemia.

Drs. Herman M. Kalckar, Elizabeth P. Anderson, and Kurt J. Isselbacher at the National Institutes of Health discovered a hitherto unknown enzyme in normal red blood cells, which they call P-Gal transferase. This enzyme, they found, is necessary to complete conversion in the body of galactose into glucose, the common sugar of the blood.

Diagnosis of galactosemia is difficult because the symptoms are similar to those of other disorders. Diarrhea, lack of appetite, loss of weight, and jaundice appear in the earlier stages. In later stages, the disease leads to cirrhosis of the liver, mental retardation, blindness due to cataract, and death.

Early recognition of galactosemia is highly important, since the disease progresses rapidly, leaving serious, irreversible changes. When diagnosed in an early stage, treatment is simple. The affected child, placed promptly on a milk-free diet, will grow. and develop normally.

The discovery of P-Gal transferase promises to provide a rather simple diagnostic test, making earlier life-saving treatment possible. It also points the way to exploration of the possibility that impairment of galactose metabolism may be a factor in other disorders of unknown origin. 